\title{
The Micropaleontological Reference Centers Network
}

by David Lazarus

doi:10.2204/iodp.sd.3.10.2006

\section{Introduction}

The Micropaleontological Reference Centers (MRCs) comprise large microfossil slide collections prepared from core samples obtained through the Deep Sea Drilling Project (DSDP) and Ocean Drilling Program (ODP). The MRCs have been maintained for three decades, largely as a volunteer effort by a global network of curators at more than a dozen institutions (Fig.1, Table 1). They were originally intended to provide a permanent micropaleontological archive for the DSDP; however, as their geographic and stratigraphic coverage has increased they have become increasingly valuable for research and teaching. This article describes the MRCs and their current usage, identifies the need to maintain and improve the accuracy of the microfossil taxonomy upon which most DSDP and ODP geochronology is based, and cites the potential for the future use of the MRCs by the Integrated Ocean Drilling Program (IODP).

\section{Distribution and Content}

The MRCs consist of eight identical sets of slides for four microfossil groups. The institutions that hold these sets provide space, microscopes, and other facilities to users of the collections, and many of the institutions contribute to the development of the MRC collections by assisting with sample selection and preparation.
Currently, the MRCs hold nearly 20,000 prepared slides for planktonic foraminifera, calcareous nannofossils, radiolarians, and diatoms. These four groups are the dominant source of biostratigraphic data for DSDP, ODP, and IODP deep-sea sediment cores. The MRC sampling strategy has always aimed at achieving comprehensive coverage for each fossil group for late Mesozoic to Recent time intervals and all oceanic regions. Samples from more than one thousand individual boreholes have provided near global, albeit nonuniform coverage, extending in some cases back to the Jurassic (Figs. 2-4). Geographically, mid-latitude central gyre regions are under-represented, particularly in the Pacific, and many more samples are available from the younger time intervals.

\section{Research Opportunities}

One general use of the MRC collections is to provide an overview of how well scientific ocean drilling has sampled the geologic record of the oceans. The patterns of recovery shown in Figures 2, 3, and 4 reflect past programmatic drilling decisions as well as the primary nature of sediment preservation in the ocean. The stratigraphic distribution of MRC samples illustrates the well-known power-law correlation of relative sediment abundance versus geologic age, and the effects of differential preservation and evolutionary change are also reflected in the relatively lower abundances

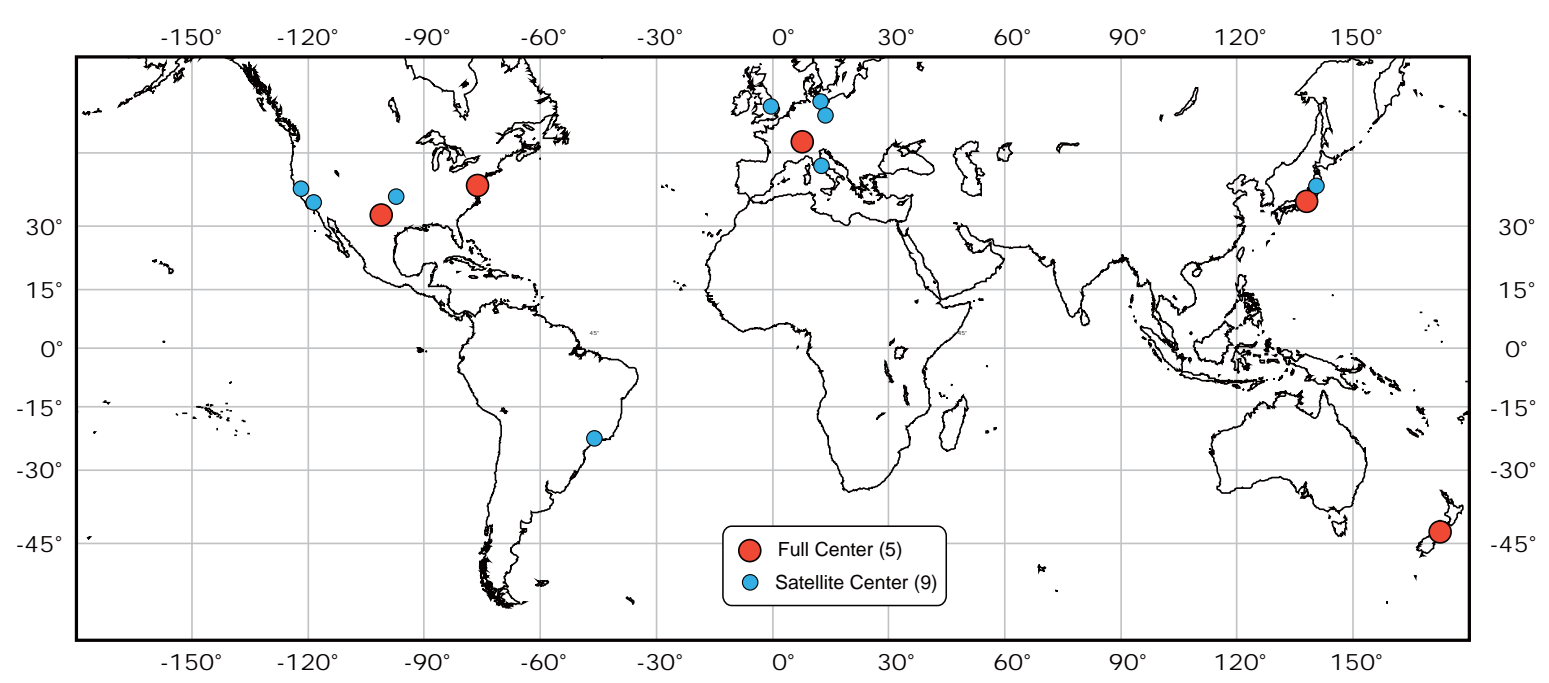

Figure 1. Locations of MRC collections. Full centers (red) hold slides for all four fossil groups. Satellite centers (blue) generally hold slides only for a single fossil group. 
Table 1: Locations of MRC collections. Full contact information can be found at http://iodp.tamu.edu/curation/mrc/institutions.html

\section{Collection}

Host Institution

City

Country

\begin{tabular}{|l|l|c|c|}
\hline Full MRCs & National Science Museum & Tokyo & Japan \\
\hline Full Collections & GNS Science & Lower Hutt & New Zealand \\
\hline Full Collections & Natural History Museum & Basel & Switzerland \\
\hline Full Collections & IODP USIO & College Station, Texas & U.S.A. \\
\hline Full Collections & Museum of Natural History & Washington, D.C. & U.S.A. \\
\hline Full Collections & & Rio de Janeiro & Brazil \\
\hline Satellite MRCs & Federal University of Rio de Janeiro & Berlin & Germany \\
\hline Foraminifera & Museum für Naturkunde & Bremen & Germany \\
\hline Radiolaria & Universität Bremen & Parma & Italy \\
\hline Foraminifera, Radiolaria & Universitá degli Studi di Parma & Utsunomiya & Japan \\
\hline Calc. Nannofossils & Utsunomiya University & Moscow & Russia \\
\hline Radiolaria & Institute of the Lithosphere & London & U.K. \\
\hline Diatoms, Foraminifera & The Natural History Museum & La Jolla, Calif. \\
\hline Calc. Nannofossils & Scripps Institution of Oceanography & Lincoln, Neb. & U.S.A. \\
\hline Radiolaria & University of Nebraska & U.S.A. \\
\hline Calc. Nannofossils, Diatoms & California Academy of Sciences & Tallahassee, Fla. & U.S.A. \\
\hline Diatoms & Florida State University & U.S.A. \\
\hline Calc. Nannofossils, Diatoms & & & Srancisco, Calif. \\
\hline
\end{tabular}

of siliceous microfossils, particularly diatoms, in Paleogene and older sediments. Such important information is readily available from the MRCs for planning future scientific drilling priorities and documenting the strengths and weaknesses in global coverage for different time intervals. As an example, the MRC collections show clearly how few deep-sea sediment samples, particularly those with siliceous microfossils, have been recovered so far for the early Paleogene, let alone the Mesozoic.

The MRC collections are also used regularly in individual research projects, with several dozen studies by curators and visitors recorded in 2004 (Fig. 5; the most recent year with compiled information available). For example, Funakawa and Nishi (2006) recently examined numerous MRC slides to determine the biogeographic affinities of nearly one hundred Paleogene radiolarian species, and they applied this information to decipher the development and spread of Antarctic water masses across the Eocene-Oligocene transition. Whereas early studies of evolutionary patterns over time were based on data from a small number of sections, more recent research in paleontology has made use of larger databases of fossil occurrences. Analyses of the Sepkoski database and its successor Paleobiology Database PBDB have yielded many valuable scientific insights, such as the importance of catastrophic extinction in the evolution of life on Earth (e.g., Lane et al., 1997). Micropaleontologists are only now beginning to conduct similar global syntheses of their data to understand how plankton diversity has evolved, responded to, and influenced climate change. Recent examples of such syntheses include an analysis of the oceanographic factors controlling recent planktonic foraminifera diversity (Rutherford et al., 1999), based on the archive of global plankton distributions created by CLIMAP (Climate: Long range Investigation, Mappping, and Prediction), and an analysis of global trends in Cenozoic diatom evolution (Finkel et al., 2005), which utilized the Neptune database of global DSDP and ODP microfossil occurrence data. Studies of previously published data are limited, however, by different priorities in measurement methods, heterogeneity of data quality, and gaps in coverage. Ultimately, new sets of systematically collected global micropaleontology data will be needed to address many important questions about longer-

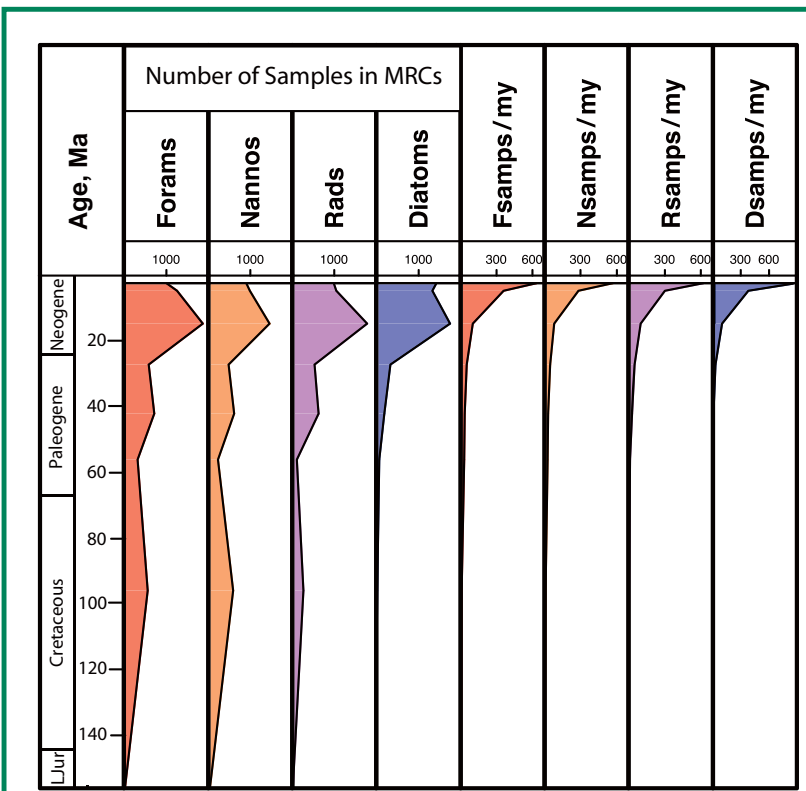

Figure 2. MRC samples vs. age, by geologic time interval. Absolute numbers in four columns on left are normalized to time interval for four columns on the right based on ages in MRC database (variable sized bins reflecting sample size-Cenozoic by epoch, Mesozoic by period). 


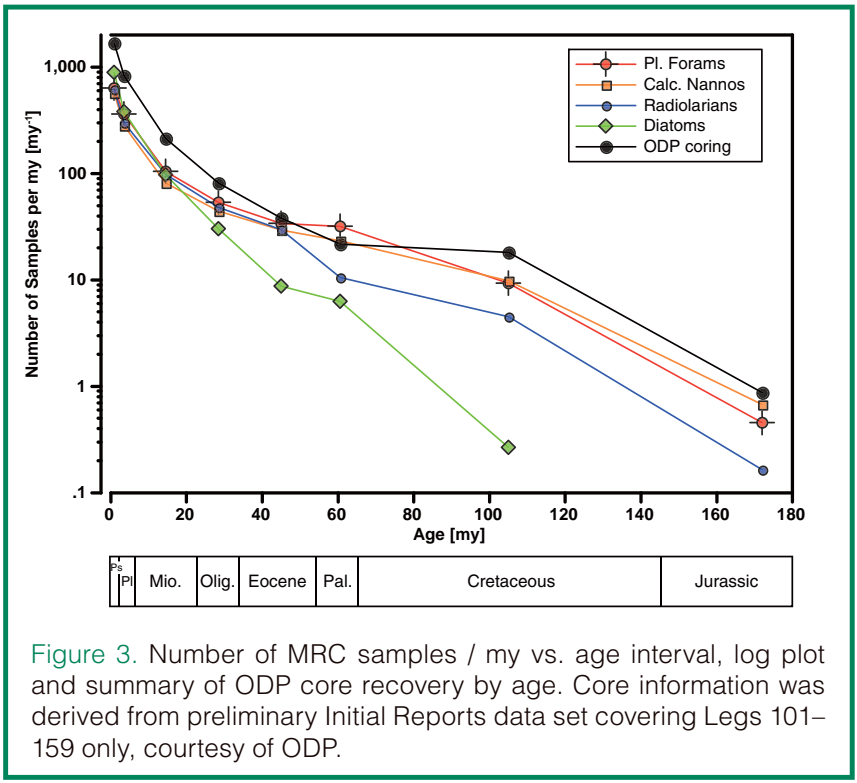

term patterns of microfossil evolution and paleoceanography. The MRCs, with their global sample coverage, represent an excellent source of ready-made materials for such studies, particularly if augmented with additional sampling of newly recovered materials from older time intervals.

\section{Maintaining Accuracy of Older Age Data}

Accurate geologic age estimates are essential for many aspects of scientific ocean drilling and other geoscience research. Age models based on time series of physical or chemical parameters and advanced methods like orbital tuning have revolutionized high-resolution chronostratigraphy, but these more-sophisticated methods still depend on a basic age-stratigraphic framework almost always provided by biostratigraphy. The concepts and definitions of species, however, continue to evolve as more morphologic, molecular, and stratigraphic data become available. As these definitions change, our ability to link old and new definitions becomes increasingly frayed. It might come as a surprise to non-specialists that many species concepts, though normally adequately documented when first defined, are not yet readily available in a single authoritative place but are instead spread throughout a large body of not always easily accessible literature. This means that we have difficulty linking older DSDP and ODP data to new data sets. This can become a serious problem because the biostratigraphic data and the age models based on them become increasingly difficult to update.

\section{Teaching and Training}

The MRC collections are also used for teaching in primary, secondary, and postsecondary education, and they provide an opportunity to train micropaleontologists prior to an ocean drilling expedition. One long-term concern identified by the paleontology working group of the IODP Scientific Technology Panel (STP) is the continued decline in the pool of taxonomic specialists required to conduct primary biostratigraphic dating of sediments recovered by scientific ocean drilling. This decline in taxonomic expertise is part of a more general trend of reduced training in taxonomic specialties in the biological sciences, but the IODP must address this issue if it wants to ensure the future availability of high-quality biochronologic data. The MRCs have already played a minor, ad hoc role in providing pre-assembled sets of suitable microfossil material to train individual scientists prior to cruises. This activity could, and perhaps should, be increased substantially in the future. One such example, made from MRC materials for shipboard use, already exists for Cenozoic tropical radiolarian stratigraphic forms (Nigrini and Sanfilippo, 2001).
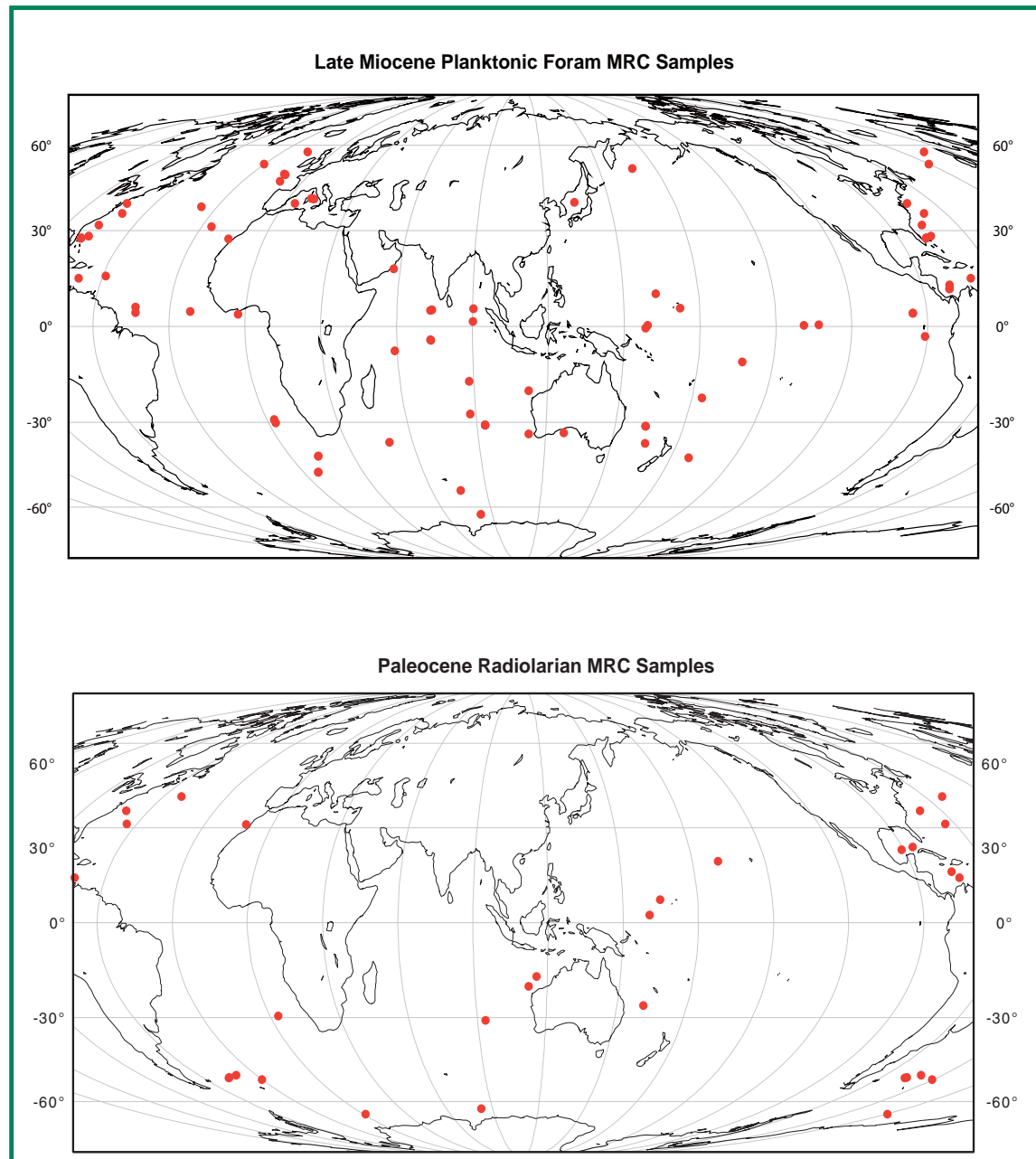

Figure 4. Location maps of MRC samples for selected time intervals. Late Miocene time interval is only half as long as Paleocene. Note: to show full Pacific basin, eastern Atlantic (and data plotted there) is duplicated on right edges of maps. 


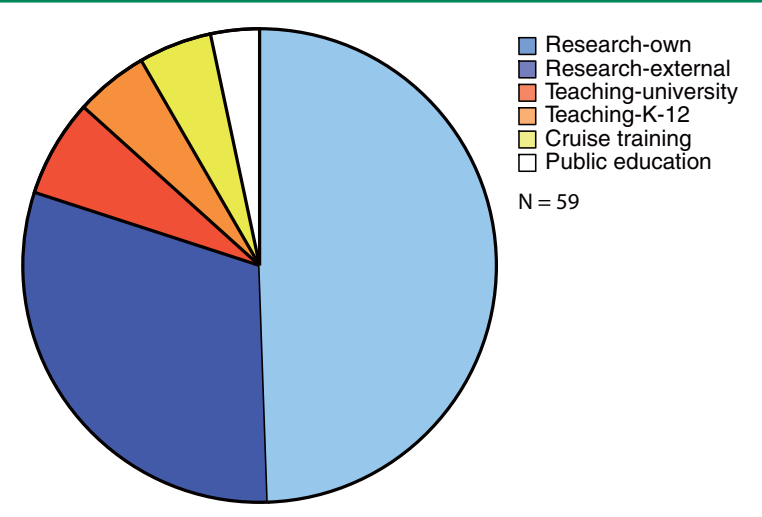

Figure 5. MRC usage in 2004, based on MRC curatorial reports.

\section{Digital Taxonomic Dictionaries}

The MRC collections can, and indeed originally were conceived to, assist in combating the above problem by providing representative specimens of biostratigraphically important microfossils from older sedimentary sections. These specimens can be examined when necessary to determine how newer taxonomic definitions map onto older materials and thereby maintain an adequate degree of uniformity in the definition of age-significant biostratigraphic data.

Now the time has come to improve substantially the community efforts to review properly and document existing species concepts in a way that they can be used as a reference standard for all IODP micropaleontology data. A lack of convenient access to taxonomic descriptions will negatively impact the IODP and ocean sciences by undermining the training of a new generation of specialists and making the re-analysis and updating of older biostratigraphic data more difficult and error-prone. The MRCs and the broader micropaleontologic community ought to meet this challenge by coordinating the development of digital taxonomic standard dictionaries, drawing on the global collections of material prepared directly from DSDP, ODP, and IODP samples. The community has already begun a dialog that could lead to major progress in this field. Scientists interested in using the $\mathrm{MRC}$ collections for research or assisting in the further development of the collections should visit the MRC Web page at http://iodp.tamu.edu/curation/mrc.html and contact the author or the nearest MRC curator (Table 1).

\section{Acknowledgements}

The author thanks the many colleagues who have volunteered their time and resources over the last thirty years to create the MRC collections. I also thank Annika Sanfilippo and Bob Goll for comments on this manuscript.

\section{References}

Finkel, Z.V., Katz, M.E., Wright, J.D., Schofield, O., and Falkowski, P. G., 2005. Climatically driven macroevolutionary patterns in the size of marine diatoms over the Cenozoic. Proc. Natl. Acad. Sci. USA, 102(25):8927-8932, doi:10.1073/pnas. 0409907102.

Funakawa, S., and Nishi, H., 2006. Radiolarian faunal change from late Middle Eocene to Late Oligocene in the Southern Ocean (Maud Rise, ODP Leg 113, Site 689). In Lüer, V., Hollis, C., Campbell, H., and Simes, J. (Eds.), Interrad 11 Programme and Abstracts: Wellington, New Zealand, (GNS Science), 56.

Lane, R.H., Steininger, F.F., Kaesler, R.L., Ziegler, W., and Lipps, J. (Eds.), 1997. Paleontology in the 21st Century: Frankfurt, Germany (Kleine Senckenbergreihe 25).

Nigrini, C., and Sanfilippo, A., 2001. Cenozoic radiolarian stratigraphy for low and middle latitudes with descriptions of biomarkers and stratigraphically useful species. ODP Tech. Note, 27 (available online, see link below).

Rutherford, S., D’Hondt, S., and Prell, W., 1999. Environment controls on the geographic distribution of zooplankton diversity. Nature, 400:749-753, doi:10.1038/23449.

\section{Author}

David Lazarus, Lead Curator, Micropaleontological Reference Centers, Museum für Naturkunde, Invalidenstrasse 43, 10115 Berlin, Germany, e-mail: david.lazarus@ rz.hu-berlin.de

\section{Related Web Links}

Main MRC web page:

http://iodp.tamu.edu/curation/mrc.html

An example of MRC based training data and linked set of prepared slides is available for Nigrini, C. and Sanfilippo, A., 2001 reference:

http://www-odp.tamu.edu/publications/tnotes/tn27/

Neptune database and NSF sponsored planktonic foraminifera DTD:

http://www.chronos.org

Example of a community supported DTD:

http://www.radiolaria.org 